\title{
Transient and steady state performance analysis of power flow control in a DFIG variable speed wind turbine
}

\author{
Cajethan M. Nwosu, Stephen E. Oti, Cosmas U. Ogbuka
}

\begin{abstract}
This paper presents transient and steady state performance analysis of power flow control in a $5.0 \mathrm{~kW}$ Doubly-Fed Induction Generator (DFIG) Variable Speed Wind Turbine (VSWT) under sub synchronous speed, super synchronous speed and synchronous speed modes of operation. Stator flux orientation is used for the control of the rotor-side converter (RSC) and DFIG whereas the grid (or stator) voltage orientation is the preferred choice for the control of the grid-side converter (GSC). In each of the three speeds modes, power is always supplied to the grid through the stator of the DFIG. The magnitude of net power (stator power plus rotor power) is less than stator power during the sub synchronous speed mode; it is greater than stator power during the super synchronous speed mode while it is equal to the stator power during the synchronous speed mode. In synchronous speed mode, the rotor power is zero indicating that power is neither supplied to the grid from the rotor nor supplied to the rotor from the grid; here the magnitude of net power is equal to stator power. The simulation results thus obtained in a MATLAB/SIMULINK environment laid credence to the controllability of power flow reversal in a DFIG-VSWT through back-to-back power electronic converter.
\end{abstract}

K e y w o r d s: doubly-fed induction generator, grid-side converter, rotor-side converter, bidirectional energy flow, decoupled control

\section{Introduction}

Vector control technique is deployed for the control of DFIG and the converters in a DFIG-VSWT. The two principle modes upon which the operation of the DFIGVSWT is based on are the sub-synchronous speed mode and super-synchronous speed mode. In sub-synchronous speed mode of operation, corresponding to positive slip of the DFIG, power is supplied to the grid only through the stator. In super-synchronous speed mode of operation, corresponding to the negative slip of the DFIG, power is supplied to the grid both through the stator and rotor.

Figure 1 shows the fundamental structure of a DFIGVSWT. Through a mechanical shaft system, the wind turbine is linked to the induction generator. The shaft system comprises a low-speed shaft and a high-speed shaft with a gearbox between the two shafts. The DFIG is supplied through both stator and rotor sides. The stator is expressly linked to the grid while the rotor is supplied through power electronic converters (PECs). Vector control must be adopted for the power flow regulation between the rotor circuit and the grid so as to generate electrical power at constant voltage and frequency to the utility grid over a wide operating range from subsynchronous to super-synchronous speeds. The PECs consist of two IGBT PWM converters, the RSC and the GSC, linked back-to-back by a DC-link capacitor. Each converter is configured for a bi-directional energy flow. The bi-directional energy flow depends on the adopted control mechanism, eg the relative amplitude of the modulating signal and its phase-shift with respect to the mains. To this end, each converter can be controlled to operate in the four quadrants.

Figure 2 is the general vector control scheme of the DFIG-VSWT. For the GSC, the control of DC-link voltage $v_{\mathrm{DC}}$, and reactive power $Q_{\mathrm{gc}}$ exchange between GSC and power grid is achieved by controlling current in synchronous reference frame. In this scheme, the d-axis of the reference frame is aligned to the stator voltage vector so that $v_{\mathrm{qs}}=0$ and $v_{\mathrm{ds}}=v_{\mathrm{s}}$. The RSC control plan comprises two vector control arrangement in cascade with inner current control loops which regulates separately the $d-q$ axes rotor currents in accordance with a given synchronously rotating reference frame. The DFIG rotor speed (or stator active power) and DFIG terminal voltage (or reactive power) are independently regulated by the outer control loop. To regulate the speed of the prime mover, in this case the wind turbine, and make the system suitable for variable speed application, one outer control loop will be for rotor speed regulation while the other will be for reactive power regulation.

Since the stator of the generator in a DFIG-VSWT system is expressly linked to the grid, both the reactive power and active power of the generator are transferred to the grid. In a sub-synchronous operation of the DFIG system, the GSC maintains the DC-link voltage constant while the RSC controls the rotor voltage in magnitude and phase angle thereby controlling the active power and reactive power of the generator. In a super-synchronous operation of the DFIG system (corresponding to the neg-

\footnotetext{
* Department of Electrical Engineering, University of Nigeria, Nsukka, Nigeria, cajethan.nwosu@unn.edu.ng, stephen.oti@unn.edu.ng, cosmas.ogbuka@unn.edu.ng
} 

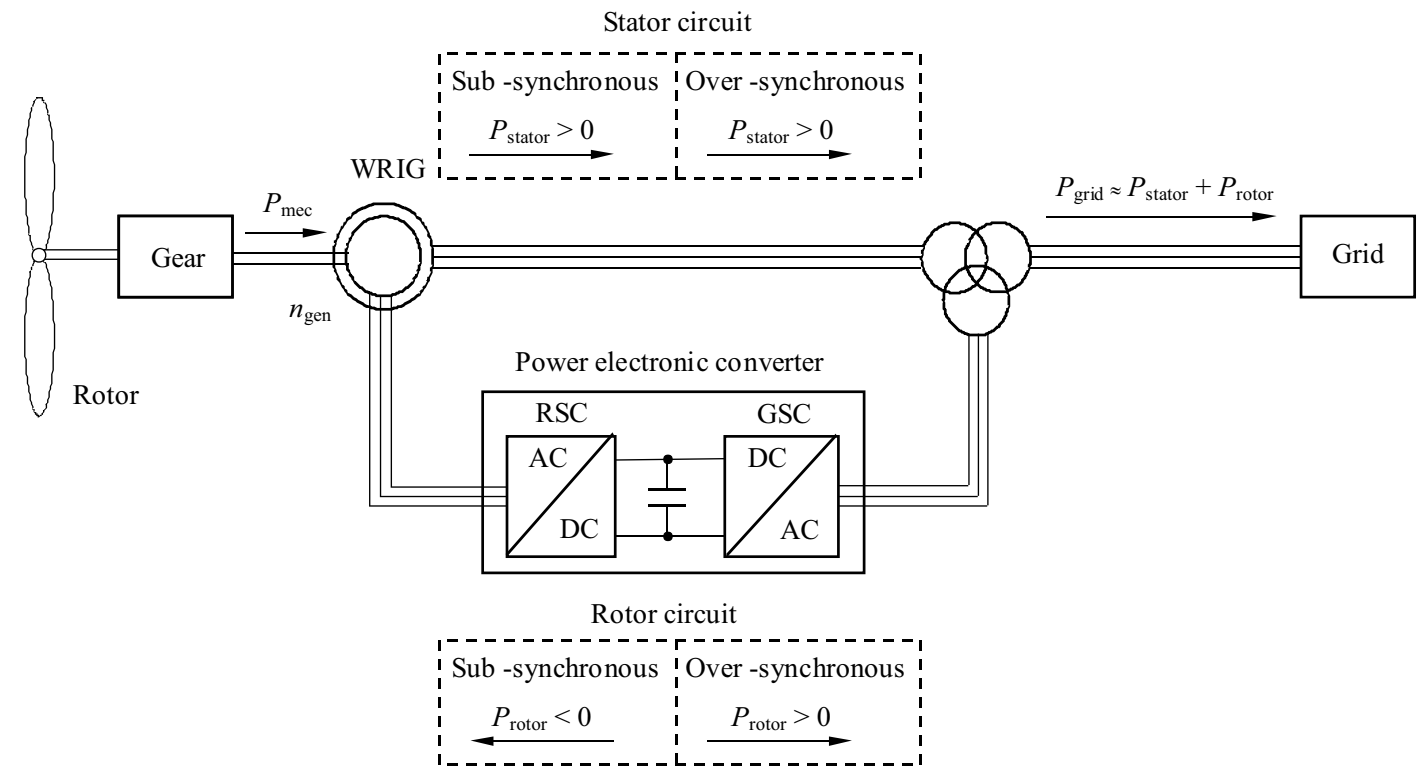

Fig. 1. Power Flow Principle in a DFIG-VSWT

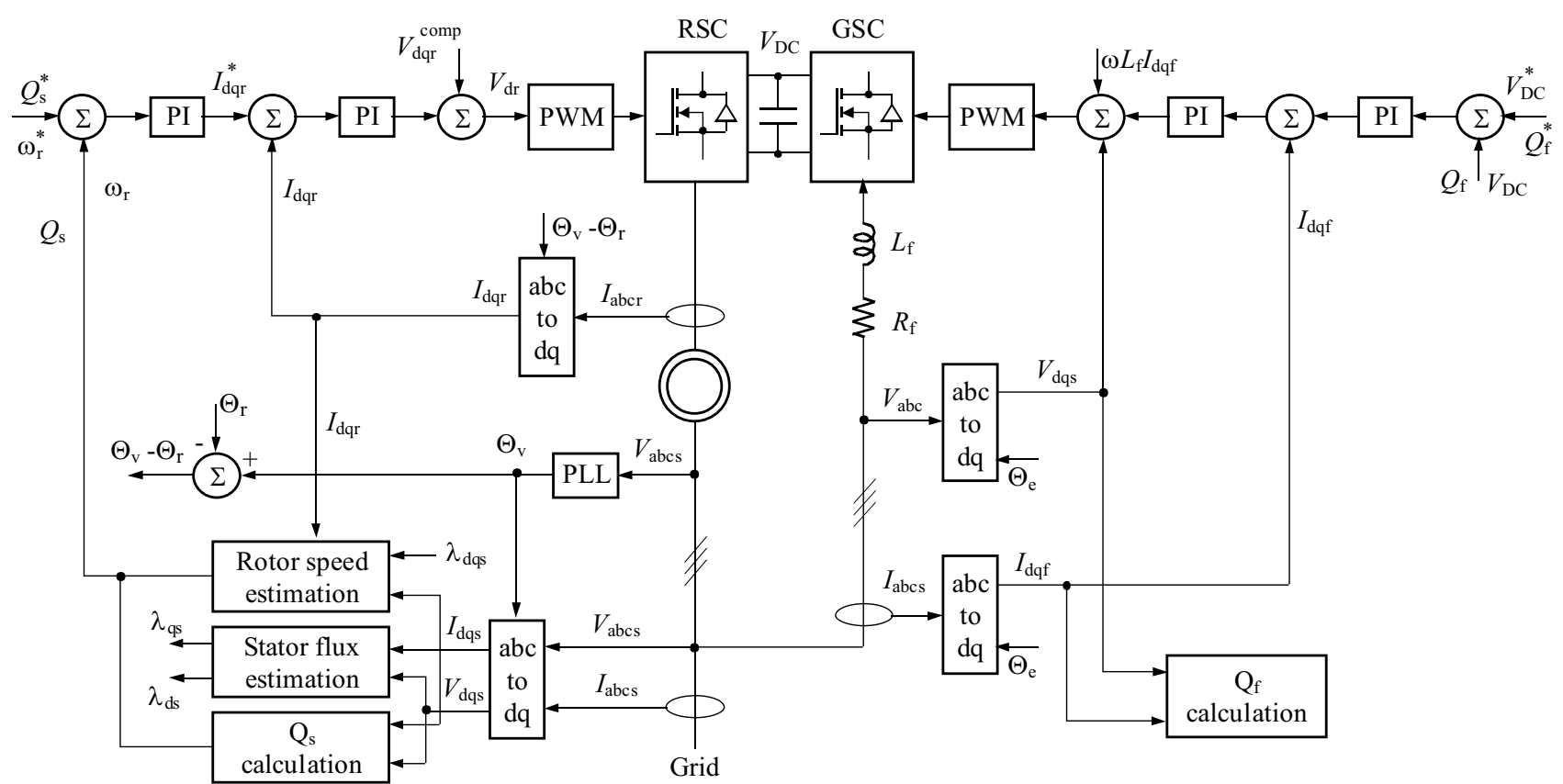

Fig. 2. Schematic diagram of the DFIG wind turbine control structure

ative slip and reversal of rotor power), the GSC can be set to control the active power and the reactive power.

\section{Converter Control Techniques}

The control of both GSC and RSC in the DFIG wind turbine is based on two cascaded control loops: a very fast inner current controller regulating the currents to the reference values. Depending on a control aim, the outer slower voltage, reactive power or speed controller may be adopted to specify the reference current values. The current controller provides reference signals in the $d-q$ axes, which are sent further to the PWM-controlled power converter.

The 3-phase currents and voltages are initially converted into an $\alpha, \beta$ stationary frame, and then into a dq reference frame rotating at the grid frequency. The supply voltage vector angular position is obtained as

$$
\theta_{e}=\int \omega_{e} \mathrm{~d} t=\tan ^{-1} \frac{v_{\beta}}{v_{\alpha}}
$$

where $v_{\alpha}$ and $v_{\beta}$ are the $\alpha, \beta$ (stationary 2-axis) stator voltage components. The angular position is utilized in transforming from the so called stationary reference 

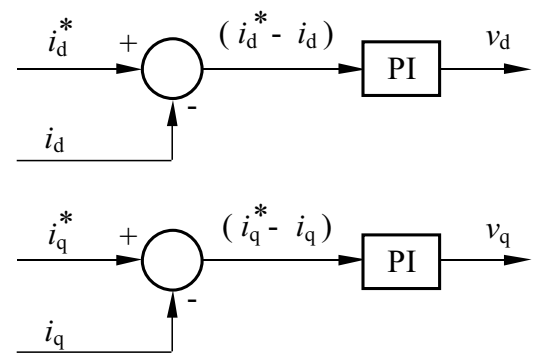

Fig. 3. Inner current control to generate $v_{d}$ and $v_{q}$

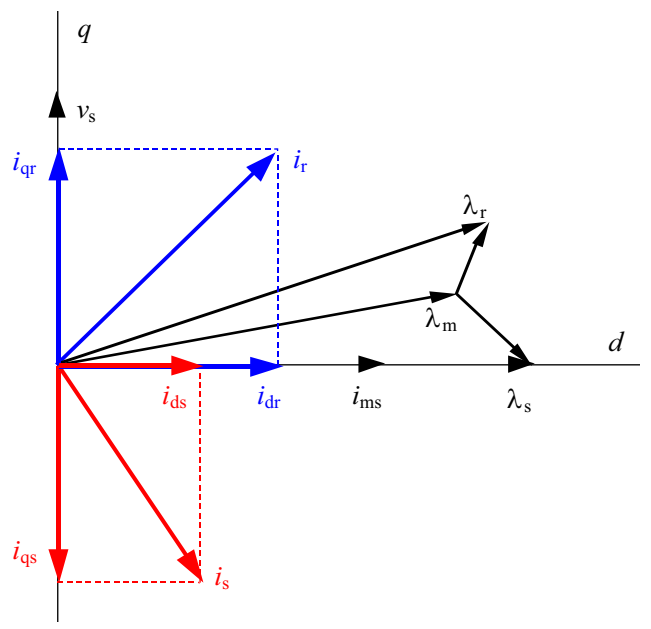

Fig. 4. Stator-flux orientation phasor diagram

frame to the rotating reference frame. The transformed $d-q$ current components $i_{d}$ and iq, are now compared with the desired values $i_{d}^{*}$ and $i_{q}^{*}$, so determined for each axis to generate error signals. The generated error signal in each axis is now PI regulated to generate voltages, $v_{d}$ and $v_{q}$ at their outputs that serve to correct for the differences between the measured (transformed) and reference values for each axis as shown in Fig. 3. Depending on a specific application, one of the desired (reference) values may be set to zero. In the control of GSC, for instance, of a back-to-back converter for DFIG wind energy system, the $q$-axis current component is set to zero for unity power factor operation. The outer slower control loop generates the reference value of the $d$-axis current. The products $\omega_{e} L i_{d}$ and $\omega_{e} L i_{q}$ known as rotational emfs and which appear as cross-coupling terms due to the transformations are compensated for to produce proper decoupling between the axes. The final resulting voltages $v_{d}$ and $v_{q}$ known as front-end converter voltages are in some cases also known as grid-side converter reference voltages. Under steady state conditions, these voltages are DC quantities. They are therefore transformed back through inverse Park, utilizing the angular position, and then through inverse Clarke to three-phase grid-side converter modulating voltages $v_{a}, v_{b}$, and $v_{c}$.

In this paper, the performances of the three synchronous speed modes of operations of DFIG-VSWT system during starting and steady state on the electrical quantities like DC-link voltages, line side voltages and currents, stator and rotor powers are verified. Detailed modeling of the wind turbine, DFIG, the controls and generation of controllers parameters for GSC and RSC are not covered in this paper. Detailed modeling of the wind turbine and DFIG can be found in literature [1-5] while treatise on the controls and generation of controllers parameters for GSC and RSC can be found in $[6,7]$.

\section{Decoupled Control of DFIG}

Stator-flux orientation is one of the three main physical coordinates to which the rotating reference frames are aligned for the decoupled-control of stator active power, reactive power and torque. The $q$-component of the flux vector is set to zero so as to link the $d$-axis of the synchronous reference frame to the stator-flux vector as

$$
\lambda_{q s}=0, \quad \lambda_{s}=\lambda_{d s} .
$$

Usually, the stator voltage vector is in quadrature advance in comparison with the stator flux vector and if the stator resistance is neglected, the $d$-axis component of the stator voltage is

$$
v_{d s}=0 \text { and } v_{q s}=v_{s} .
$$

The stator voltage and flux equations now become

$$
\begin{aligned}
0 & =R_{s} i_{d s}+p \lambda_{d s}, \\
v_{q s} & =R_{s} i_{q s}+\omega \lambda_{q s}, \\
\lambda_{d s} & =L_{s} i_{d s}+L_{m} i_{d r}, \\
0 & =L_{s} i_{q s}+L_{m} i_{q r} .
\end{aligned}
$$

From (8) the $q$-component of the stator current is

$$
i_{q s}=-\frac{L_{m}}{L_{s}} i_{q r}
$$

Substituting (9) into the relation $\lambda_{q r}=L_{r} i_{q r}+L_{m} i_{q s}$ yields

$$
\lambda_{q r}=\sigma L_{r} i_{q r}
$$

Where $\sigma=1-L_{m}^{2} / L_{s} L_{r}$ is known as rotor leakage factor. Under stator-flux orientation, the stator flux is

$$
\lambda_{s}=\lambda_{d s}=L_{m} i_{m s}=L_{s} i_{d s}+L_{m} i_{d r}
$$

From (11) the $d$-components of the current are related as

$$
i_{d s}=\frac{L_{m}}{L_{s}}\left(i_{m s}-i_{d r}\right)
$$

Substituting (12) into the relation $\lambda_{d r}=L_{r} i_{d r}+L_{m} i_{d s}$ yields

$$
\lambda_{d r}=\frac{L_{m}^{2}}{L_{s}} i_{m s}+\sigma L_{r} i_{d r} .
$$


Representing the slip-speed $\left(\omega-\omega_{r}\right)$ in stator-flux orientation as $\omega_{s l}$, the model of the $d-q$ rotor voltages are

$$
\begin{aligned}
& v_{d r}=R_{r} i_{d r}+\sigma L_{r} p i_{d r}-\omega_{s l} \sigma L_{r} i_{q r} \\
& v_{q r}=R_{r} i_{q r}+\sigma L_{r} p i_{q r}+\omega_{s l} \sigma L_{r} i_{d r}+\omega_{s l} \frac{L_{m}^{2}}{L_{s}} i_{m s} .
\end{aligned}
$$

The stator-flux orientation sets the $P_{s}, Q_{s}$ and $T_{e}$ equations as

$$
\begin{gathered}
P_{s}=\frac{3}{2} v_{q s} i_{q s}, \\
Q_{s}=\frac{3}{2} v_{q s} i_{d s}, \\
T_{e}=\frac{3}{2} \frac{P}{2} \lambda_{d s} i_{q s} .
\end{gathered}
$$

Here, $i_{q s}$ which controls the $P_{s}$, and $T_{e}$ is related to the $i_{q r}$ as

$$
i_{q s}=-\frac{L_{m}}{L_{s}} i_{q r} .
$$

The injection of $i_{q r}$ will result in proportionate change in the $i_{q s}$ to control the $P_{s}$, and $T_{e}$.

The reactive power control current $i_{d s}$, is related to $i_{d r}$ as

$$
i_{m s}=k i_{d s}+i_{d r}
$$

where $k=L_{s} / L_{m}$. The injection of $i_{d r}$ will naturally lead to smaller value of $i_{d s}$ being drawn from the stator terminals and therefore improves the stator power factor. The process of this control is explained in Fig. 4.

For the control of the RSC and DFIG the stator flux orientation is adopted while the grid (or stator) voltage orientation is the preferred choice for the control of the GSC.

\section{Selection of Control Bandwidths}

It is recommended that the angular switching frequency $\omega_{s w}$ of the converter switches should at least be five times the closed-loop bandwidth $\omega_{0}$ [8] for stable operation of the system

$$
\omega_{s w} \geq 5 \omega_{0}
$$

Using this formula and the relation $t_{r}=\ln 9 / \omega_{0}$, the switching frequency (in hertz) can be related to the rise time

$$
f_{s w} \geq \frac{5 \ln 9}{2 \pi t_{r}} \approx \frac{1.75}{t_{r}} .
$$

An odd frequency modulation ratio of 39 is chosen for the GSC. This sets the switching frequency and the approximate angular switching frequency to $1950 \mathrm{~Hz}$ and $12252 \mathrm{rad} / \mathrm{s}$ respectively. The closed-loop bandwidth may then be calculated as

$$
\omega_{0} \leq \frac{\omega_{s w}}{5} \leq \frac{12252}{5} \leq 2450 \mathrm{rad} / \mathrm{s} .
$$

Closed-loop bandwidth of $2250 \mathrm{rad} / \mathrm{s}$ is chosen for all the GSC and RSC inner-current control loops, while closedloop bandwidth one tenth of the inner-current value or

\begin{tabular}{|c|c|c|c|c|c|}
\hline$R_{\mathrm{s}}$ & $1.06], \Omega$ & $V_{\mathrm{s}}$ & $400 \mathrm{~V}$ & $v_{\text {nom }}$ & $10 \mathrm{~m} / \mathrm{s}$ \\
\hline$L_{\mathrm{ls}}$ & $1.401 \mathrm{mH}$ & & & $v_{\text {cut-in }}$ & $4 \mathrm{~m} / \mathrm{s}$ \\
\hline$R_{\mathrm{r}}$ & $0.8 \Omega$ & $L_{\mathrm{f}}$ & $12 \mathrm{mH}$ & $J_{\text {turb }}$ & $7.5 \mathrm{kgm}^{2}$ \\
\hline$L_{\mathrm{lr}}$ & $1.46 \mathrm{mH}$ & $R_{\mathrm{f}}$ & $0.1 \Omega$ & $n_{\text {gear }}$ & 5.14 \\
\hline$L_{\mathrm{m}}$ & $66.4 \mathrm{mH}$ & $C$ & $2.4 \mathrm{mF}$ & $\xi$ & 0.6 \\
\hline$\Sigma$ & 0.0417 & & & $c$ & 10.8 \\
\hline$J_{\mathrm{DFIG}}$ & $1.5 \mathrm{kgm}^{2}$ & $P_{\text {nom }}$ & $5 \mathrm{kV}$ & $K_{\mathrm{s}}$ & 1.0 \\
\hline$P$ & 6 & $R$ & $3 \mathrm{~m}$ & $R$ & \\
\hline
\end{tabular}

$225 \mathrm{rad} / \mathrm{s}$ is selected for all the outer loops controls. The controllers parameters for the overall control of the DFIGVSWT are obtained by pole placement technique through comparison of characteristic polynomials of resulting controllers transfer functions with the second order Butterworth polynomials [1]. Table 1 gives the overall DFIG wind turbine components parameters from which the controllers parameters and other parameters are calculated.

Table 1. Overall DFIG wind turbine components parameters

\section{Lookup table}

A lookup table is generated for a $5.0 \mathrm{~kW}$ VSWT with a rated wind speed of $10 \mathrm{~m} / \mathrm{s}$. Using the data as presented in Table 1 , the optimum tip-speed ratio $\lambda_{\text {opt }}$ and a corresponding maximum power coefficient $C_{p, \max }$ of 7.95 and 0.4322 respectively are obtained. This corresponds to the wind turbine rotor speed of $26.5 \mathrm{rad} / \mathrm{s}$ at the rated wind speed and power of $10 \mathrm{~m} / \mathrm{s}$ and $5.0 \mathrm{~kW}$ respectively. We assume the $26.5 \mathrm{rad} / \mathrm{s}$ wind turbine rotor speed to correspond to 130 per cent of the generator synchronous speed (ie $\left.\omega_{\text {gen,rated }}\right)$ and is obtained as

$$
\begin{aligned}
\omega_{\text {gen,rated }} & =\omega_{s}+0.3 \omega_{s}, \\
\omega_{s} & =\frac{4 \pi f}{P} .
\end{aligned}
$$

\begin{tabular}{|c|c|c|c|c|c|}
\hline$V(\mathrm{~m} / \mathrm{s})$ & $\omega_{\mathrm{tr}}(\mathrm{rad} / \mathrm{s})$ & $\omega_{\operatorname{gen}}(\operatorname{rad} / \mathrm{s})$ & $T_{e}^{\mathrm{ref}}(\mathrm{Nm})$ & $i_{q r}^{\mathrm{ref}}(\mathrm{A})$ & $T_{\text {shaft,gen }}(\mathrm{Nm})$ \\
\hline 4 & 10.60 & 54.484 & 43.09 & -6.44 & -77.17 \\
\hline 5 & 13.25 & 68.105 & 67.32 & -10.06 & -79.12 \\
\hline 6 & 15.90 & 81.726 & 96.95 & -14.49 & -79.70 \\
\hline 7 & 18.55 & 95.347 & 132.00 & -19.72 & -78.91 \\
\hline 8 & 21.20 & 108.968 & 172.40 & -25.76 & -76.76 \\
\hline 9 & 23.85 & 122.589 & 218.10 & -32.60 & -73.24 \\
\hline 10 & 26.50 & 136.210 & 269.30 & -40.25 & -68.35 \\
\hline
\end{tabular}

For a 6 -pole DFIG, $\omega_{\text {gen,rated }}=136.136 \mathrm{rad} / \mathrm{s}$ from which $n_{\text {gear }}$ is determined to be 5.14 where

$$
n_{\text {gear }}=\frac{\omega_{\text {gen }}}{\omega_{t r}} .
$$

Table 2 is the lookup table for MPPT operation of the DFIG-VSWT at different wind speeds between the cut-in and rated.

Table 2. Lookup table for MPPT of the DFIG-VSWT 


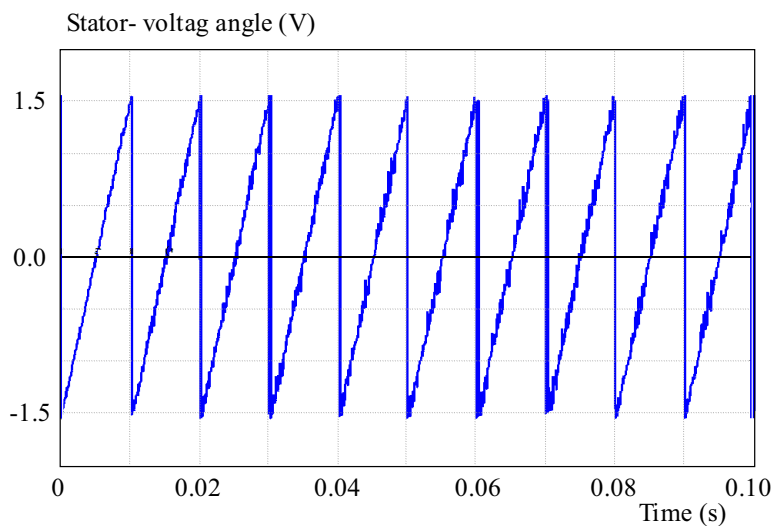

Fig. 5. Stator voltage vector position

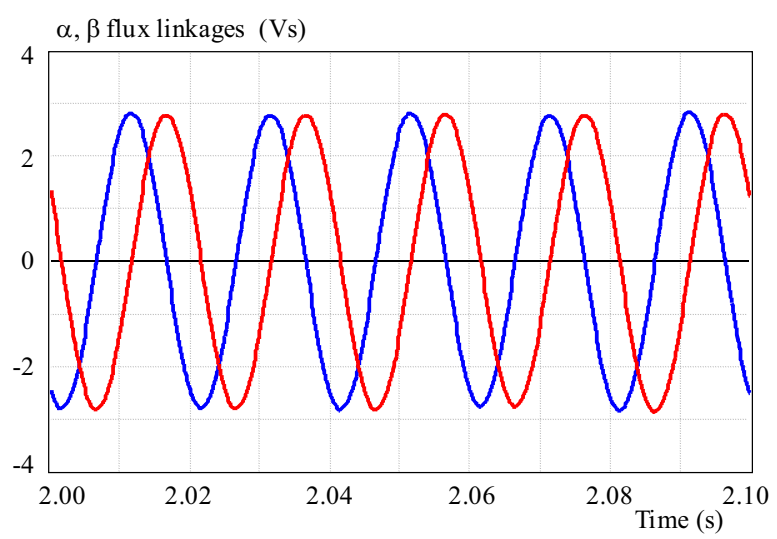

Fig. 7. The $\alpha-\beta$ stator flux linkages

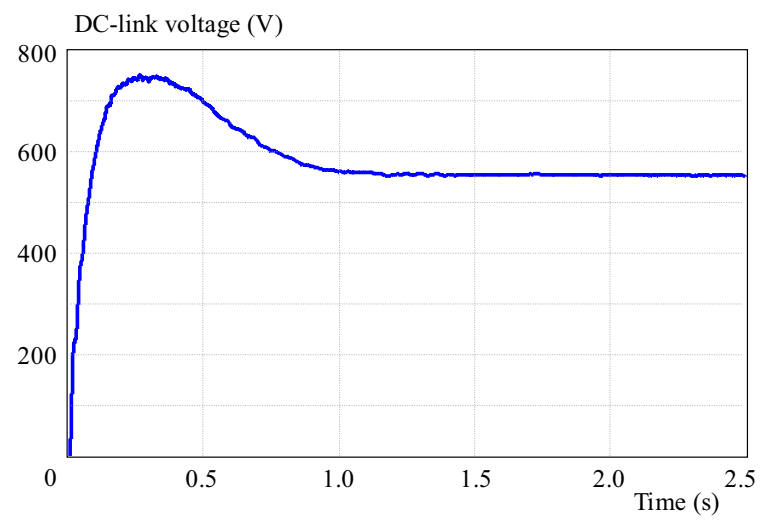

Fig. 9. DC-link voltage

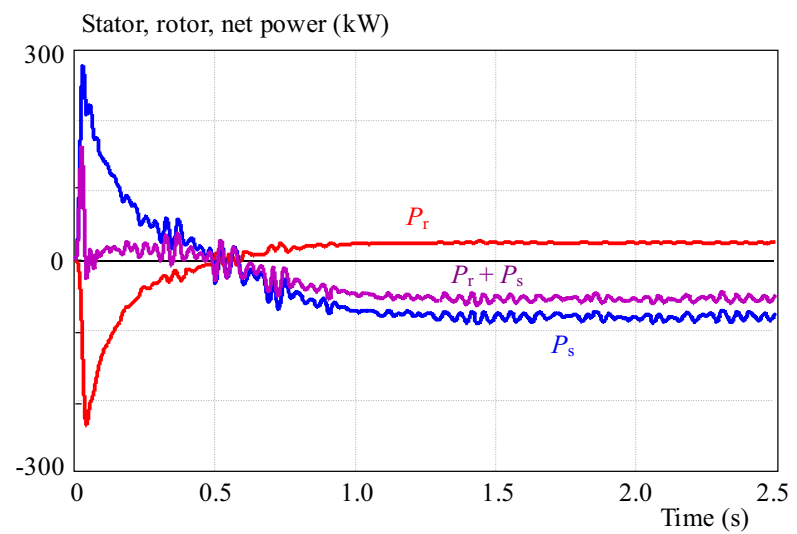

Fig. 11. The $\alpha-\beta$ stator flux linkages

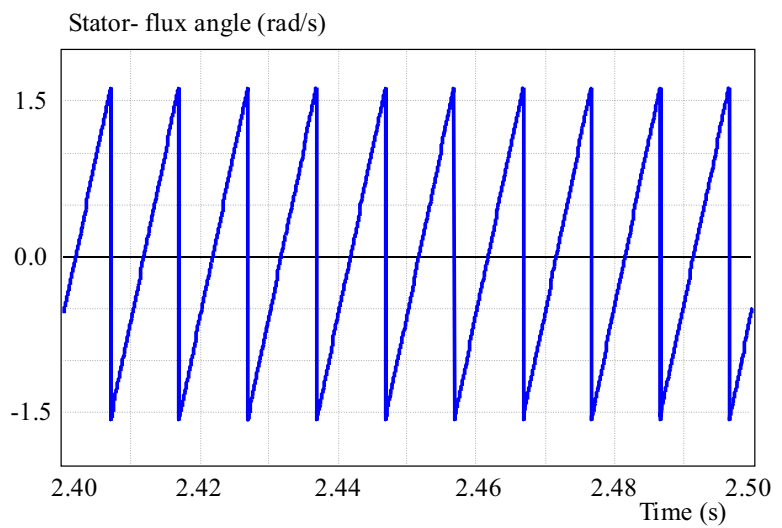

Fig. 6. Stator flux vector position

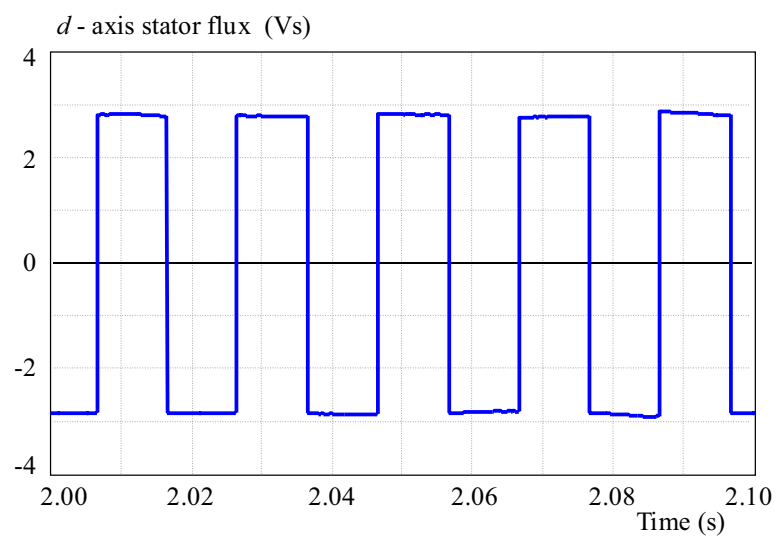

Fig. 8. The $d$-component of the stator flux linkage

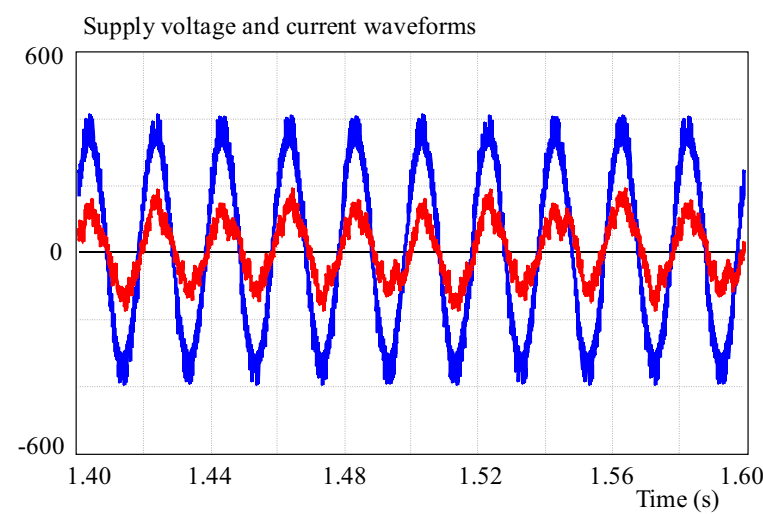

Fig. 10. The steady state supply side voltage and current waveforms

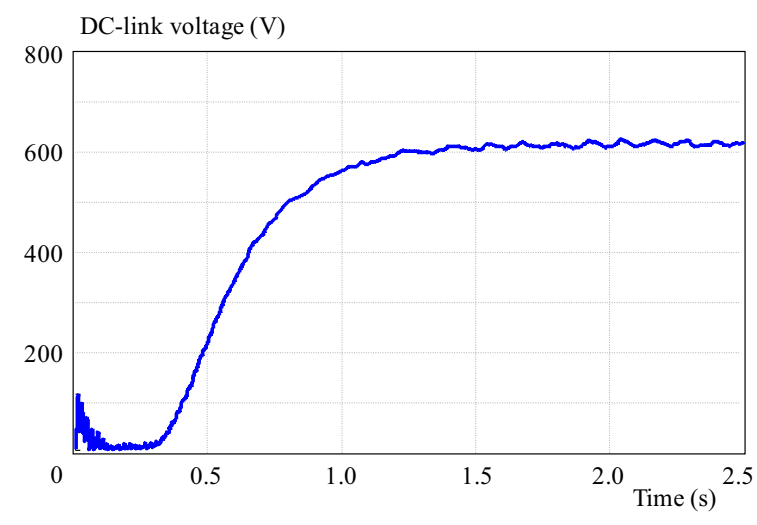

Fig. 12. The stator, rotor and net powers 
For a damping ratio $\xi=0.6$ and rotor inertia $=$ $7.5 \mathrm{kgm}^{2}$, damping coefficient $c$ and low-speed shaft stiffness $K_{s}$ of 10.8 and 1.0 respectively are obtained. The shaft torque at the generator input at different rotor speed may be obtained from

$$
T_{\text {shaft,gen }}=\frac{1}{n_{\text {gear }}}\left[10.8\left(\omega_{r}-26.5\right)+\int\left(\omega_{r}-26.5\right) \mathrm{d} t\right] .
$$

\section{Simulation results}

Figure 5 is the stator voltage vector position while Fig. 6 is the stator flux vector position. The $\alpha-\beta$ stator flux linkages are displayed in Fig. 7 while the $d$ component of the stator flux linkage is shown in Fig. 8. These preliminary generated waveforms and others not displayed here are necessary for the investigation of the sub-synchronous, super-synchronous and synchronous operating modes of the DFIG wind turbine system.

\subsection{Sub-synchronous speed mode}

In the three operating modes, the requirements are that the GSC modulation index $\mathrm{m} 1$ be kept constant at 0.75 while the RSC modulation index is varied in relation to the operating speeds (slips) of the DFIG at different operating modes. For the sub-synchronous speed mode, a rotor speed $\omega_{r}$, corresponding to $\omega_{s}-0.3 \omega_{s}$ or $73.304 \mathrm{rad} / \mathrm{s}$ is chosen. The corresponding operating slip of 0.3 is obtained. From the look-up table, these operating speed and slip correspond to wind speed of between $5 \mathrm{~m} / \mathrm{s}$ and $6 \mathrm{~m} / \mathrm{s}$. The rotor speed is scaled down through the wind turbine gearbox ratio to $14.261 \mathrm{rad} / \mathrm{s}$ and then used in $(27)$ to generate the generator shaft torque of $-79.46 \mathrm{Nm}$. For the $400 \mathrm{~V}$ DFIG stator voltage, the rotor slip voltage and the RSC modulation depth are established as $120 \mathrm{~V}$ and 0.39 respectively. Figure 9 is the DC-link voltage regulated to $550 \mathrm{~V}$. Displayed in Fig. 10, are the steady state supply side voltage and current waveforms showing a near unity displacement factor between the waveforms. To achieve the near unity displacement factor, the $i_{q s}^{*}$ is set to zero. The stator, rotor and net

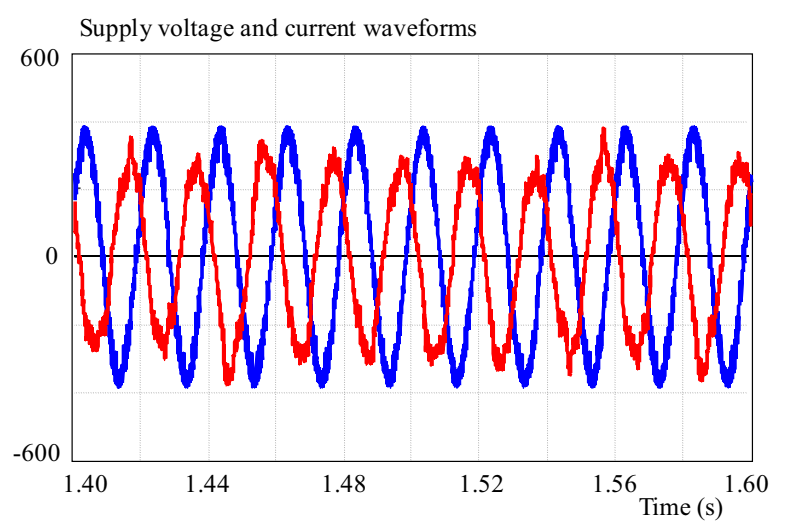

Fig. 13. The steady state supply side voltage and current waveforms powers are displayed in Fig. 11. The net power is the sum of the stator and rotor powers. The stator power is negative indicating that power is supplied to the grid through the stator of the DFIG. The rotor power is positive indicating that power is supplied to the rotor from the grid through the back-to-back converters. The net power is also negative indicating that more power is supplied to the grid than is taken from the grid. The magnitude of the net power is however less than the magnitude of the stator power.

\subsection{Super-synchronous speed mode}

For the super-synchronous speed mode, a rotor speed $\omega_{r}$, corresponding to $\omega_{s}+0.3 \omega_{s}$ or $136.136 \mathrm{rad} / \mathrm{s}$ is chosen. The corresponding operating slip of -0.3 is obtained. From the look-up table, these operating speed and slip correspond to the rated wind speed of $10 \mathrm{~m} / \mathrm{s}$. The rotor speed is scaled down through the turbine gearbox ratio to $26.5 \mathrm{rad} / \mathrm{s}$ and then used in (27) to generate the generator shaft torque of $-68.31 \mathrm{Nm}$. For the $400 \mathrm{~V}$ DFIG stator voltage, the rotor slip voltage and the RSC modulation depth are established as $-120 \mathrm{~V}$ and 0.39 respectively. Shown in Fig. 12, is the DC-link voltage also regulated to $550 \mathrm{~V}$. Displayed in Fig. 13 are the steady state supply side voltage and current waveforms. In this mode, the phase displacement between the phase voltage and current is near $180^{\circ}$. The GSC which under sub-synchronous speed mode functions as a rectifier now operates as an inverter while the RSC now operates as a rectifier. Like in the sub-synchronous speed mode, GSC $i_{q s}^{*}$ is also set to zero.

The stator, rotor and net powers are displayed in Fig. 14. Like in the sub-synchronous speed mode, the stator power is negative indicating that power is supplied to the grid through the stator of the DFIG. The rotor power is in this mode negative indicating that power is also supplied to the grid form the DFIG rotor through the back-to-back converters. The net power is more negative than the stator power. The magnitude of the net power is therefore more than the magnitude of the stator power.

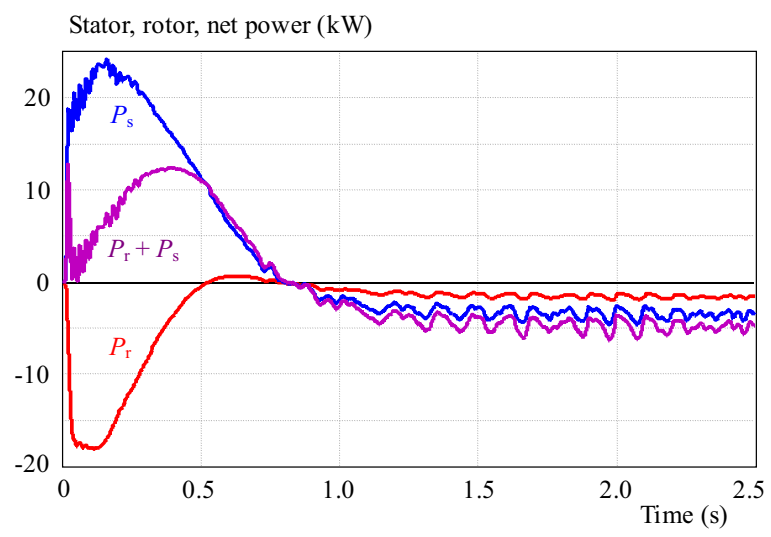

Fig. 14. The stator, rotor and net powers 


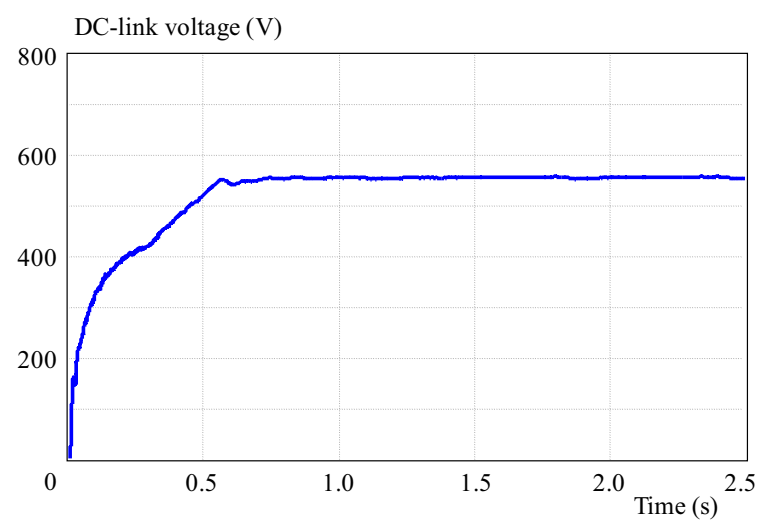

Fig. 15. DC-link voltage

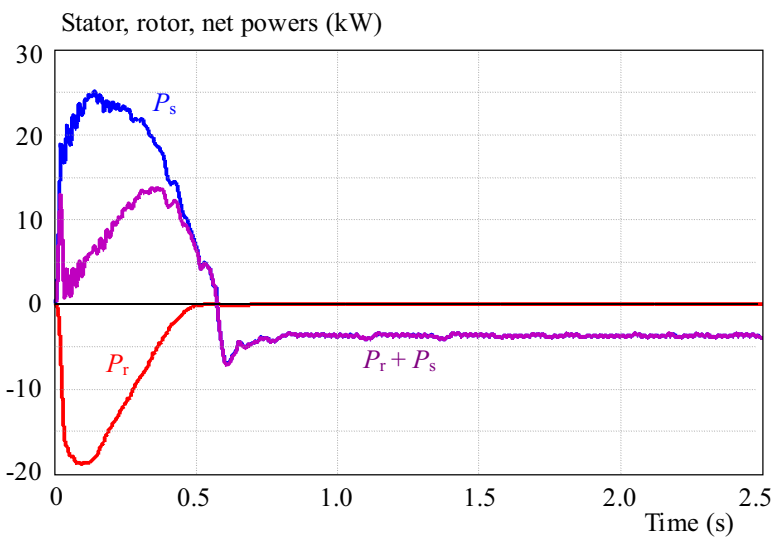

Fig. 17. The stator, rotor and net powers

\subsection{Synchronous speed mode}

For the synchronous speed mode, a rotor speed $\omega_{r}$ equal to $\omega_{s}$ or $104.72 \mathrm{rad} / \mathrm{s}$ is chosen. This corresponds to zero operating slip. From the look-up table, this operating speed corresponds to wind speeds between $7 \mathrm{~m} / \mathrm{s}$ and $8 \mathrm{~m} / \mathrm{s}$. The rotor speed is scaled down through the turbine gearbox ratio to $20.374 \mathrm{rad} / \mathrm{s}$ and then used in (27) to generate the generator shaft torque of $-77.55 \mathrm{Nm}$. The rotor slip voltage is by this arrangement equal to zero while the RSC modulation depth is zero or near zero in practice.

Shown in Fig. 15, is the DC-link voltage again regulated to $550 \mathrm{~V}$. Displayed in Fig. 16 are the steady state supply side voltage and current waveforms. The phase displacement between the phase voltage and current is in this mode near $0^{\circ}$. The grid-side $i_{q s}^{*}$ is also set to zero in this speed mode. The stator, rotor and net powers are displayed in Fig. 17. The stator power is also negative in the synchronous speed mode indicating that power is supplied to the grid through the stator of the DFIG. The rotor power in this mode is zero. The net power in steady state is equal to the stator supplied power as is shown in Fig. 17.

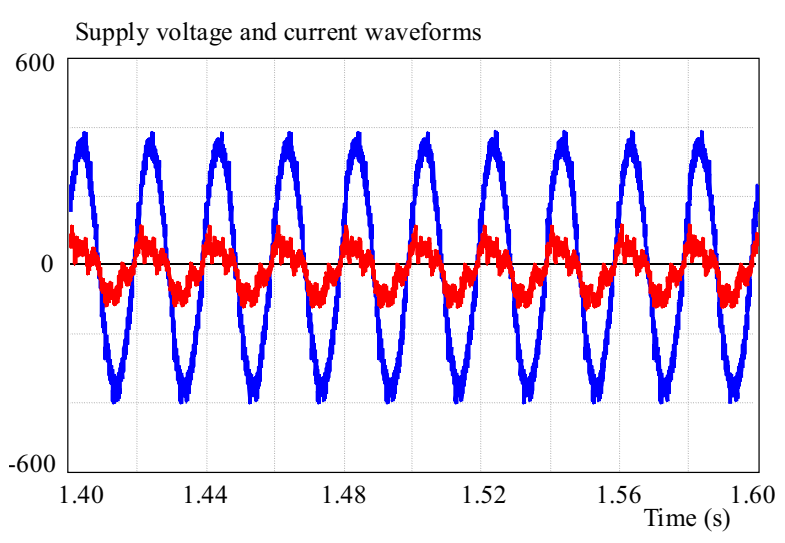

Fig. 16. The steady state supply side voltage and current waveforms

\section{Discussion}

The discussions are based on the starting transient and steady state performances of the power flow control of an example $5.0 \mathrm{~kW}$ DFIG-VSWT. In the three speed modes, the stator power is positive over certain period of time with peak value depending on the controller setting. The positive value of the stator power indicates that power is supplied to the DFIG from the grid through the stator at starting until the DFIG rotor runs to its nominal speed at which the stator power goes negative and because of the dynamic relationship between rotor speed and DC-link voltage the time at which the DC-link voltage assumes steady state value may be taken as the time the rotor speed settles to a steady state. For the analysis presented the stator powers peak at $25 \mathrm{~kW}$ for super-synchronous and synchronous speed modes and a little above $27 \mathrm{~kW}$ for sub-synchronous speed mode. These peak values can be accommodated depending on the protection method or minimized depending on the starting or control techniques utilized.

Irrespective of speed mode of operation, the rotor power is always negative within the period before the rotor runs to the nominal speed and because the magnitude of rotor power is less than the magnitude of stator power within this period, the net power is positive in each case.

The steady state performance analysis of the $5.0 \mathrm{~kW}$ DFIG-VSWT show that power is supplied to the rotor from the grid through the back-to-back converters during sub synchronous speed mode; here the magnitude of net power (stator power plus rotor power) is less than stator power. In super synchronous speed mode power is supplied to the grid from the rotor through the back-to-back converters; here the magnitude of net power is greater than stator power. In synchronous speed mode, the rotor power is zero indicating that power is neither supplied to the grid from the rotor nor supplied to the rotor from the grid; here the magnitude of net power is equal to stator power. 


\section{Conclusions}

Steady state performance analysis of power flow control in a $5.0 \mathrm{~kW}$ DFIG-VSWT under sub synchronous speed, super synchronous speed and synchronous speed modes of operation is presented.

The stator voltage and stator flux vector positions as well as the $\alpha-\beta$ stator flux linkages, the $d$-component of the stator flux linkage and other waveforms not displayed are first generated for the investigation of the subsynchronous, super-synchronous and synchronous speeds of operation corresponding to rotor speed $\omega_{r}$, of $\left(\omega_{s}-\right.$ $\left.0.3 \omega_{s}\right),\left(\omega_{s}+0.3 \omega_{s}\right)$ and $\left(\omega_{s}\right)$ respectively.

The GSC modulation index is kept constant at 0.75 in the three operating modes and hence the DC-link voltage is maintained constant at $550 \mathrm{~V}$ while the RSC modulation index is varied in relation to the operating speeds (slips) of the DFIG at each of the operating modes.

In sub synchronous speed mode, power is supplied to the rotor from the grid through the back-to-back converters; here the magnitude of net power is less than stator power. In super synchronous speed mode power is supplied to the grid from the rotor through the back-to-back converters; here the magnitude of net power is greater than stator power. In synchronous mode, the rotor power is zero indicating that power is neither supplied to the grid from the rotor nor supplied to the rotor from the grid; here the magnitude of net power is equal to stator power.

It is observed that the reactive power of the generator in each of the three speed modes is always transferred to the grid. In the sub-synchronous speed mode the control of the reactive power is excised on the RSC while in the super-synchronous operation speed mode the control of the reactive power is excised on the GSC.

The simulation results of the steady state performance analysis support the unique power flow reversal controllability of DFIG-VSWT with the help of back-to-back power electronic converter. The results of the analysis will serve as a first hand base and guide for wind turbine design and operation engineers.

\section{REFERENCES}

[1] H. M. Hasanien and E. A. Al-ammar, "Dynamic Response Improvement of Doubly Fed Induction GeneratorBased Wind Farm using Fuzzy Logic Controller", Journal of Electrical Engineering, vol. 63, no. 5, 2012, 281-288.

[2] B. Pokharel, Modeling, Control and Analysis of a Doubly Fed Induction Generator Based Wind Turbine System with Voltage Regulation, MSc Thesis, Tennessee Technical University, 2011.

[3] L. Hannefors and H. P. Nee, "Model-Based Current Control of AC Machines using the Internal Model Control Method", IEEE Trans. Ind. Applicat., vol. 34, no. 1, 1998, 133-141.

[4] R. Pena, J. C. Clare and G. M. Asher, "Doubly Fed Induction Generator using Back-to-Back PWM Converters and its Application to Variable-Speed Wind-Energy Generation", IEE Proc.-Electr. Power Appl., vol. 143, no. 3, 1996, 231-234.

[5] O. Kamel, O. Mohand, R. Toufik and N. Taib, "Nonlinear Predictive Control of Wind Energy Conversion System using DFIG with Aerodynamic Torque Observer", Journal of Electrical Engineering, vol. 65, no. 6, 2014, 333-341.

[6] C. A. Nwosu, Back-to-Back Power Electronic Converter Control for Active Damping, Germany, LAP Lambert Academic Publishing, 2012, 71-102.

[7] C. A. Nwosu and C. U. Ogbuka, "Analysis and Verification of the Effects of Active Damping on the Dynamic Performance of a Grid-Side Converter ", Elektrika, vol. 13, 2013, 12-20.

[8] N. Rumzi, N. Idris and H. M. Yatim, "An Improved Stator Flux Estimation in Steady-State Operation for Direct Torque Control of Induction Machines ", IEEE Trans. Ind. Applicat., vol. 38, 2012, 110-116.

Received 20 June 2016

Cajethan Nwosu (Engr, Dr) was born 1st October 1967. He obtained the BEng, MEng, and PhD Degrees in Electrical Engineering from the University of Nigeria, Nsukka in 1994, 2004, and 2015 respectively. In 2007, he undertook a three months pre-doctoral research on Wind/Solar Hybrid Power System and Renewable Energy Resources at the University of Technology, Delft (TU-Delft), the Netherlands. Since 2005, he has been with the Department of Electrical Engineering, University of Nigeria, Nsukka, where he is currently a Senior Lecturer. He had written two books and had published over thirty articles both in local and international journals. He is an executive member of Nigerian Institution of Electrical and Electronic Engineers (NIEEE), Nsukka chapter. He is a member of Power Electronics Society of Institution of Electrical and Electronic Engineering (PES IEEE). He is an editorial board member World Science Journal of Engineering Applications. His areas of research interest include power electronic converters, electrical drives and renewable energy technologies.

Stephen Ejiofor Oti (Engr, Dr) was born in 1974. He obtained the BEng, MEng, and PhD Degrees in Electrical Engineering from the University of Nigeria, Nsukka in 1998, 2006, and 2014 respectively. In 2000, he was engaged as Senior Mathematics Teacher in Special Science School, Nsukka from where he joined the Electrical Engineering Department, UNN as a Principal Technical Officer and was later in 2007 converted to the lecturing cadre in the same department. He is a member of Nigerian Society of Engineers (NSE) and is also a registered member of Council for the Regulation of Engineering in Nigeria (COREN). His research areas include Machine modeling, Thermal modeling, Power and Energy systems modeling and Simulations.

Cosmas Ogbuka (Engr, Dr) was born in Umuna Nigeria on 1st April, 1981. He received his BEng (First Class Honors), MEng (Distinction) and PhD in 2004, 2009 and 2014 respectively in the Department of Electrical Engineering University of Nigeria, Nsukka, where he presently works as a Lecturer I. His research interests are in Adjustable Speed Drives of Electrical Machines: (DC and AC Electric Machine Torque/Speed Control with Converters and Inverters), Electric Machines and Power Electronics. He has published both locally and internationally and attended conferences within and outside Nigeria. He is a member of Nigerian Society of Engineers (NSE), Nigerian Institution of Electrical Engineers (NIEEE), International Association of Engineers (IAENG) and is registered by the Council for the Regulation of Engineering in Nigeria (COREN). He is presently on a postdoctoral research visit at the Chair of Electrical Drives and Actuators (EAA) Universität der Bundeswehr München, Germany with Professor Dr-Ing Dieter Gerling. 